\title{
Growth patterns in male rats exposed to concurrent long-term environmental challenges
}

\author{
Cuervo $\mathrm{PF}^{1^{*}}$, Racca $\mathrm{AL}^{1,2}$, Beldomenico $\mathrm{PM}^{1,2}$
}

1 Laboratorio de Ecología de Enfermedades, Instituto de Ciencias Veterinarias del Litoral (ICIVET-Litoral), Universidad Nacional del Litoral - Consejo Nacional de Investigaciones Científicas y Tecnológicas (UNL - CONICET), Esperanza, Santa Fe, Argentina.

2 Facultad de Ciencias Veterinarias del Litoral, Universidad Nacional del Litoral (UNL), Esperanza, Santa Fe, Argentina.

* Correspondence: Pablo F. Cuervo, Laboratorio en Ecología de Enfermedades (LEcEn), ICIVET Litoral (UNL - CONICET), RP Kreder 2805, Esperanza, Santa Fe, Argentina (CP 3080). E-mail: pablofcuervo@gmail.com

Received: 26 July 2016. Accepted: 18 October 2016. Available online: 21 October 2016

Editor: C. Baravalle

\begin{abstract}
SUMMARY. Growth is a key determinant of fitness in animals, and may be affected by the environmental challenges presented over the course of an individual's lifespan. When faced with limited resources and environmental challenges, organisms may prioritize the development and maintenance of particular processes over others. To expand our understanding of the consequences of organism exposure to a changing environment, we offer a long-term experiment to compare the growth patterns of young male rats exposed and not exposed to food limitation and social conflict. The patterns of growth of young rats were altered by the exposure to these environmental challenges, two of the most frequently faced by animals. As expected, scarcity of food resulted in a marked growth decline in animals exposed to nutritional stress. Interestingly, individuals exposed to an unstable social environment, but fed ad libitum, evidenced a growth rate $6 \%$ smaller than those under stable social conditions. An interaction between food limitation and social conflict was not observed. As a larger body size growth results in a competitive advantage in encounters, the detected divergence on growth patterns may represent significant consequences on the individual's life trajectory.
\end{abstract}

RESUMEN. Patrones de crecimiento en ratas macho expuestas de manera prolongada a desafíos ambientales concurrentes. En animales, la eficacia biológica es influenciada por el crecimiento, que a su vez es afectado por los desafíos ambientales que el individuo enfrente a lo largo de su vida. Ante escasez de recursos u otros desafíos, los organismos priorizarían el desarrollo y mantenimiento de algunos procesos por sobre otros. Para profundizar nuestro conocimiento sobre las consecuencias de la exposición a un ambiente cambiante, desarrollamos un experimento de larga duración para comparar los patrones de crecimiento de ratas jóvenes expuestas y no expuestas a restricción alimentaria y conflicto social. La exposición a estos dos desafíos ambientales, comunes en la naturaleza, alteró los patrones de crecimiento de las ratas. La escasez de alimento ocasionó un descenso marcado del crecimiento en los animales bajo restricción alimentaria. Mientras que individuos expuestos a inestabilidad social, pero con alimento ad libitum, demostraron una tasa de crecimiento $6 \%$ menor que aquellos en condiciones sociales estables. Adicionalmente, no se encontró interacción significativa entre restricción alimentaria y conflicto social. Siendo que un mayor crecimiento corporal resulta ventajoso ante interacciones competitivas, la diferencia detectada entre los patrones de crecimiento tendría consecuencias de importancia en la trayectoria de vida de los individuos.

Key words: social conflict, food restriction, body mass

Palabras clave: conflicto social, restricción alimentaria, masa corporal

\section{Introduction}

In animals, the intraspecific individual variation in size, mass and body condition are associated with the individual's competitive interactions, ability on the use of resources, foraging behaviour, anti-predator defences, exposure and resistance to parasites (Blanckenhorn, 2000; Griffiths and Brook, 2005; Burthe et al., 2010; Bolnick et al., 2011; Preisser and Orrock, 2012; Okie et al., 2013; Yan et al., 2014). For instance, larger individuals are better able to compete for resources, usually have higher reproductive output, are less-likely to be predated and experience a lower cost of foraging reductions (Berner and Blanckenhorn, 2007; Muñoz and Bonal, 2008; Preisser and Orrock, 2012). In addition, individuals in a good body condition are better prepared to face and limit an infection (Beldomenico and Begon, 2010). In consequence, growth is a key determinant of fitness for many animals.

It is well known that many factors affect growth over the course of an individual's lifespan, not only food availability, but also population density, competition, 
and health factors as well as other environmental challenges (Griffiths and Brook, 2005; English et al., 2012; Lee et al., 2012; Schmidt et al., 2012). When faced with limited resources and environmental challenges, organisms may prioritize the development and maintenance of particular processes over others, thus inducing a trade-off between these processes (e.g. between growth and immunity) (Burthe et al., 2010; Bolnick et al., 2011; Kriengwatana et al., 2013). Additionally, the impact over growth patterns may depend on the developmental phase at which the environmental challenges are encountered (Kriengwatana et al., 2013). Due to the numerous physiological processes that mature at diverse developmental phases, growth might be differentially affected if environmental challenges are experienced early (e.g., peri-pubertal or juvenile phase) or later in development (e.g., late-juveniles) (Kriengwatana et al., 2013).

Since many characteristics of an organism are related in some way to body size, understanding the factors affecting their variation is particularly relevant. Assessing the impact over growth of two frequent environmental challenges (resource limitation and social conflict) can expand our understanding of the consequences of organism exposure to a changing environment. We performed a long-term experiment in young male rats to explore the impact of food limitation and social conflict on growth patterns. We hypothesized that long-term food limitation and social conflict (social instability + crowding), either alone or acting synergistically, alter the growth patterns of rats. We expect that the animals exposed to the environmental challenges would decrease their investment in growth.

\section{Materials and Methods}

\section{Animals and housing conditions}

Young male rats (Rattus norvegicus, var. Wistar) were obtained at 4 weeks of age $(n=24)$ from the breeding colony maintained at CMC - ICIVET Litoral (Centro de Medicina Comparada, Instituto de Ciencias Veterinarias del Litoral). Males were selected because dominance hierarchies in rats are stronger and tend to influence a wider range of behaviours in males than in females (Blanchard et al., 2001). Two weeks before the start of the experiment (acclimation period), the rats were randomly selected and distributed into eight groups (three animals in each of eight polysulfona cages of 274 x $443 \times 231 \mathrm{~mm}$ ) in an experimental room with 24-h light/dark 12:12 cycle. The cages were placed in a commercial cage-rack, with individual HEPA-filtered ventilation (Allentown ${ }^{\circledR}$ ). Temperature was kept at $21 \pm$ 2 ㅇ $\mathrm{C}$ and relative humidity was maintained at $50 \pm 5 \%$. Commercial rat chow and tap water were available $a d$ libitum throughout the acclimation period. The two- week acclimation period was used to carry out baseline comparisons. In addition, other eight animals (defined as "intruders") were kept in the same conditions as in the acclimation period, to be later used to impose the social conflict (see below).

\section{Experimental procedures}

$A 2^{2}$ experimental design with food restriction $(F R+)$ and social conflict $(\mathrm{SC}+)$ as the independent variables was used to test the hypothesis. After the acclimation period, the rats were randomly selected and assigned to one of the four experimental groups (two replicates each): i) Control (FR-SC-) ( $n=4,2$ per replicate); ii) Food restriction (FR+SC-) $(n=4,2$ per replicate); iii) Social conflict (FR-SC+) $(n=8,4$ per replicate); and iv) both stressors (FR+SC+) ( $n=8,4$ per replicate). Baseline comparisons were used with the analysis of variance (ANOVA) test to verify that body mass, body length (measured from nose to base of tail) and body mass index (log body mass/log body length [Labocha et al., 2014]) were similar between groups prior to the start of the experiment (for these baseline comparisons, $p=0.1$; for the main analyses, $p=0.05)$. A timeline and the experimental design are provided in Figure 1 ( $A$ and $B$ ).

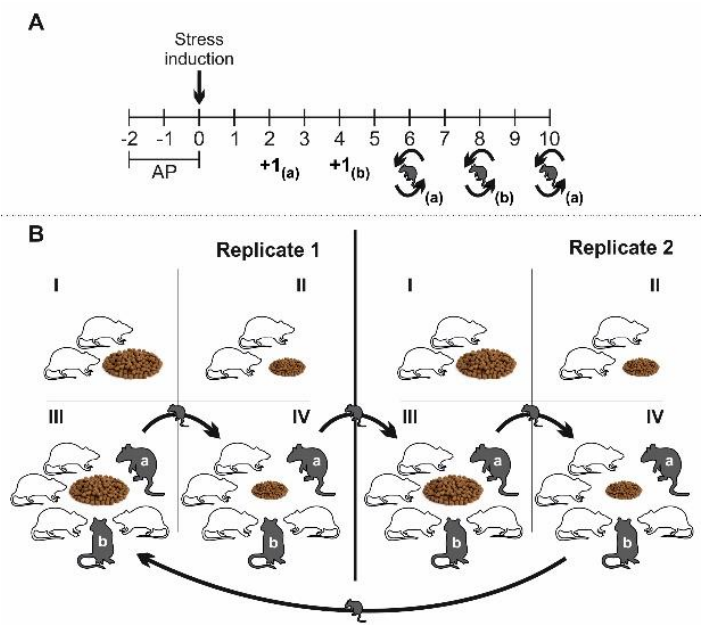

Figure 1. Timeline and experimental design. AP: acclimation period; Treatments=I: Controls (FR-SC-); II: Food restriction (FR+SC-); III: Social conflict (FR-SC+); IV: Both stressors $(\mathrm{FR}+\mathrm{SC}+)$; white rats: animals under study; grey rats: intruder animals; $+1_{(\mathrm{a})}$ : addition of the first intruder animals; $+1_{(\mathrm{b})}$ : addition of the second intruder animals; intruder animals.

The treatments were implemented for 10 consecutive weeks. FR-SC- groups were fed ad libitum and the animal density was kept low and stable (2 per cage). In consequence, FR-SC- refers to an absence of food restriction and an absence of social conflict. Animals under FR+ were fed $60 \%$ of the mean food intake of those individuals fed ad libitum in the FR-SC- groups (Kristan, 2007). The SC+ treatment accounted both for social instability and for crowding (where proximity was the mechanism of social stress) (Blanchard et al., 2001). To achieve high densities at the beginning of the 
experiment, the $\mathrm{FR}-\mathrm{SC}+$ and $\mathrm{FR}+\mathrm{SC}+$ groups started with four animals per cage (Fig 1B). Thereafter, to maintain social instability and increase the cage density, a randomly selected intruder animal was added to the group every two weeks, until reaching a maximum density of six animals per cage (Fig $1 \mathrm{~A}$ and $1 \mathrm{~B}$, grey rats). Once the maximum density was reached, the intruder animals were translocated between $\mathrm{SC}+$ groups. The intruder animals were not sampled and not considered in the analyses performed.

\section{Stress measurement}

The levels of total plasma corticosterone (CORT) was measured at the beginning and the end of the experiment ( 0 and 13) to verify the induction of measurable stress by the treatments. CORT values were obtained from diethyl ether extracted plasma aliquots $(15 \mu \mathrm{l})$ using a radioimmunoassay, following Jahn et al. (1995). In addition, as the alteration of the adrenal histo-architecture is a known consequence of chronic stress (Nicolaides et al., 2015; Ulrich-Lai et al., 2006), we compared the relative masses of the zona fasciculata and zona glomerulosa from the adrenal cortex. The net and relative sizes of the zona fasciculata and zona glomerulosa were obtained by the morphometric analysis of the stained sections with hematoxylin and eosin.

\section{Food intake}

Since subjects were housed in groups of two or more individuals, food intake was evaluated, on a daily basis, considering the cage as the unit of analysis $(n=8)$. Each day and according to the established treatments, a weighed ration of a commercial rat chow was provided on a wire cage lid. The ration of food provided was adjusted in consideration of the number of rats in each cage. In the next day, the food intake was estimated, in grams, by weighing the food remaining in each cage (the bedding material was thoroughly revised to include food drops). As a measure of food intake we considered the weekly relative per capita food intake (relFI): (weekly consumption per cage/number of individuals) /body mass of each individual.

\section{Growth and body condition}

The animals were weighed and measured on a weekly basis. The measures of growth and body condition considered were: weekly body mass (wBM), weekly body mass gain (wBMG), and weekly body mass index = log body mass/log body length (Labocha et al., 2014) (wBMI).

Growth patterns in mammals are modelled with a nonlinear function of age, best characterized by a sigmoid equation (Zullinger et al., 1984). The parameters obtained from the most common non-linear models can be used for comparisons, both across and within species, as they control for differences in body size (Griffiths and Brook, 2005; English et al., 2012). To characterize body mass development, the weekly weights of each specimen from six until 16 weeks of life were fitted to three growth models frequently used in mammals: the Gompertz, logistic, and Richards equations (Zullinger et al., 1984). Then the best fit was assessed based on the Akaike Information Criterion (AIC), and growth parameters were extracted from the best model. This procedure has been automated in the "grofit" R library (Kahm et al., 2010). The Gompertz model provided the best fit overall (for wBM: Gompertz: $42 \%$ of the individuals considered, logistic: $33 \%$, and Richards: $25 \%$ ), in agreement with previous studies on rodents growth (Antinuchi and Luna, 2002; Jackson and Van Aarde, 2003; De Conto and Cerqueira, 2007). Therefore, the procedure was forced to fit only the Gompertz model to allow inter-individual comparisons (Merkling et al., 2012). The parameters obtained for each specimen were the lag time $\lambda$ until rapid growth occurs, the maximum growth rate represented by the maximum slope $\mu$, and the maximum growth $A$ represented by the upper asymptote (Zullinger et al., 1984; Merkling et al., 2012).

\section{Statistical analysis}

The longitudinal measures of food intake, growth and body condition were analysed with linear mixed models (LMM), including random intercepts to account for the lack of independence of observations from the same animal and the same cage. The response variables considered were relFI, WBM, WBMG and WBMI. The initial models had the main effects FR and SC, and the interaction term $\mathrm{FR}^{*} \mathrm{SC}$, to consider the effect of each stressor, as well as the potential synergism between them. The term "week" was included as independent variable, with linear and quadratic terms, both as main effects and interactions with treatments. The models included "Individual ID", nested within "cage ID", as a random intercept to account for the repeated measures.

The maximum growth rate $\mu$ and the maximum growth $A$, obtained from the Gompertz growth model, were used as response variables in a LMM. The maximum growth rate $\mu$ indicates the increase of mass per unit of time during the phase of rapid growth. The maximum growth $A$ (the upper asymptote), where the slope of the growth curve reaches zero, refers to the maximum body mass reached by the sampled group. The lag time $\lambda$ was included in the growth curve to describe the shape of the curve, but it was not considered as a response variable because mass values were not available until 28 days of age, and thus the parameter did not incorporate the previous biologically relevant growth (from day 0 to 28) (Downs et al., 2016). The treatments applied (FR and SC) and the interaction term $\mathrm{FR} * \mathrm{SC}$ were considered as independent variables. The term "cage ID" was included as a random intercept to take into account that groups of observations belonged to the same cage. 
The measures of stress were analysed with LMM, which included the interaction term FR*SC and "Cage ID" as a random intercept.

The distribution of the response variables was checked for normality and transformed when required. The relevance of the interactions was evaluated with the second-order Akaike Information Criterion (AICC) (Johnson and Omland, 2004; Arnold, 2010; Burnham et al., 2011). When the inclusion of the interaction did not reduce $\mathrm{AICc}$ values in 2 or more units $(\triangle \mathrm{AICc}<2)$, it was dropped from the model, and only the main effects were retained (whether significant or not).

All analyses were undertaken using the statistical software " $R$ " (R Development Core Team 2007) using the packages Ime4 and languageR (functions Imer and pvals.fnc, respectively) (Eberhardt et al., 2013).

\section{Ethical considerations}

All the procedures were performed according to the "Guide for the Care and Use of Laboratory Animals" (ILAR, 2010) and the protocol was approved by the ethics and safety committee of the Facultad de Ciencias Veterinarias of the Universidad Nacional del Litoral (Santa Fe, Argentina) under protocol number 135/12.

\section{Results}

\section{Stress measurement}

At the end of the experiment, the CORT levels were significantly increased in FR+ animals (FR and FR+SC groups) when compared to FR- ( $C$ and SC groups) ( $p<$ 0.001 ), while no changes were detected in those $S C+$ ( $\mathrm{SC}$ and $\mathrm{FR}+\mathrm{SC}$ groups). Furthermore, $\mathrm{FR}+$ animals had greater relative masses of the zona fasciculata ( $p=$ 0.019 ) and zona glomerulosa $(p=0.027)$. The individuals exposed to social conflict ( $\mathrm{SC}+$ ) tended to have a smaller relative mass of the zona glomerulosa $(p=0.073)$.

\section{Food intake}

As a consequence of the food restriction forced by the treatment, at the beginning of the experiment the relFI was much greater in FR- animals that in those FR+ (Fig. $2 \mathrm{~A}$, Table $\mathrm{S} 1$ in on-line supplementary material). However, this difference became gradually smaller as the weeks progressed and disappeared by the end of the experiment. Meanwhile, SC+ individuals slightly decreased their food intake in relation to body mass along the entire experiment (Fig. 2A, Table S1).
A

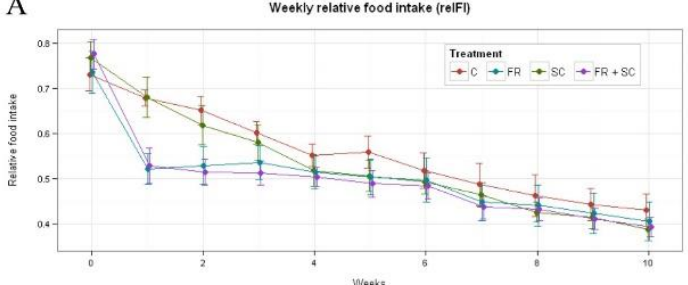

B

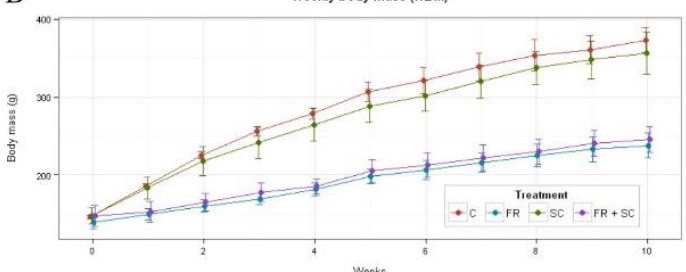

$\mathrm{C}$

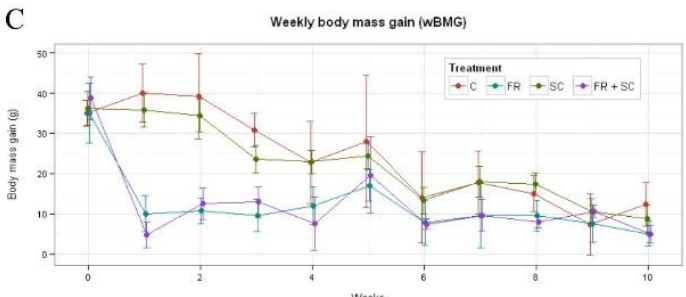

D

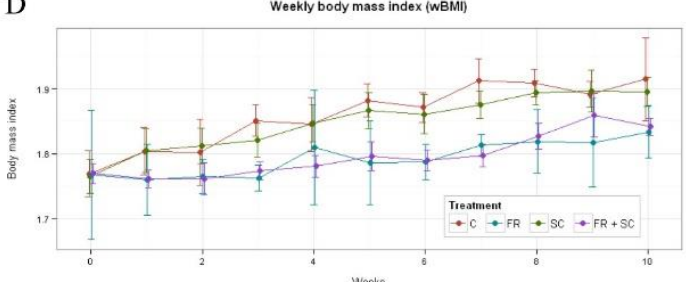

Figure 2. Effect of treatments over selected measures of food intake and growth. A: Weekly relative food intake; B: Weekly body mass; C: Weekly body mass gain; $\mathrm{D}$ : Weekly body mass index. [C = FR-SC-; FR = FR+SC-; SC = FR-SC+; FR + SC = FR+SC+].

\section{Growth and body condition}

Individuals exposed to food restriction evidenced a much slower growth than those with free access to food (evidenced by the WBM and the growth parameters) (Fig. 2B, Tables1 and S2). The maximum growth rate $\mu$ greatly differed among treatments, with $\mathrm{FR}+$ animals growing around $13 \mathrm{~g} /$ week as compared with the 38.6 $\mathrm{g} /$ week grew by the FR-SC- (Table 1). On the other hand, the animals exposed to social conflict but fed ad libitum (FR-SC+), grew per week 6 g less than those FR-SC(Table 1). Additionally, by the end of the experiment, the WBMG was similar among treatments, apparently because the FR- animals reached their adult size and naturally detained their growth (Fig. $2 \mathrm{C}$ and Table S3). Surprisingly, the maximum growth represented by the upper asymptote $A$ did not differ among treatments (Table 1). Regarding the weekly body mass index (wBMI), the difference between the FR+ individuals and those FR- increased over time at first, but started to diminish by the middle of the experiment (Fig. 2D and Table S4). 
Table 1. Linear mixed model describing the effect of treatments on selected growth parameters $(A, \mu)$.

\begin{tabular}{|c|c|c|c|c|c|}
\hline Term & Estimate & SE & $T$ & $\boldsymbol{P}$ & $\triangle \mathrm{AICC}$ \\
\hline \multicolumn{6}{|c|}{$\boldsymbol{\mu}$ - model: Imer $\left(\mu^{\sim S C}{ }^{*} \mathrm{FR}+(1 \mid\right.$ cage ID $\left.)\right)$} \\
\hline Intercept & 38.6 & 1.7 & 22.7 & $<0.001$ & \\
\hline SC & -6.1 & 2.1 & -2.9 & 0.008 & \\
\hline FR & -25.8 & 2.4 & -10.7 & $<0.001$ & \\
\hline $\mathrm{SC} * \mathrm{FR}$ & 7.0 & 2.9 & 2.4 & 0.028 & 2.3 \\
\hline \multicolumn{6}{|c|}{$\boldsymbol{A}$ - model: Imer(A SC+FR+(1|cage ID $))$} \\
\hline Intercept & 390.1 & 23.3 & 16.8 & $<0.001$ & \\
\hline SC & 11.5 & 24.8 & 0.5 & 0.648 & -2.6 \\
\hline FR & -38.6 & 23.7 & -1.6 & 0.119 & -2.5 \\
\hline
\end{tabular}

SE: standard error; $T$ : $T$-value; $P$ : $P$-value

\section{Discussion}

The growth patterns of young adult male rats were altered by exposure to two of the environmental challenges most frequently faced by animals. As expected, scarcity of food resulted in a marked growth decline, with a maximum growth rate $67 \%$ smaller in FR+ animals as compared to FR-SC-. Interestingly, the individuals exposed to an unstable social environment, but fed ad libitum, decreased their food intake in relation to body mass, which resulted in a maximum growth rate $6 \%$ smaller than those under stable social conditions. Additionally, and despite a reasonable expectation (Creel et al., 2013; Dantzer et al., 2013), an interaction between food limitation and social conflict was not observed in our results.

It is known that body size growth is constrained by the amount of energy available and the maintenance expenditure of individuals (Gursoy et al., 2001; Griffiths and Brook, 2005). The abrupt decline of weekly body mass gain (WBMG) experienced by the rats with restricted resources reflected an attempt to allocate the resources acquired to fulfil maintenance costs, reducing the resources directed to somatic growth. The limitation of growth to diminish maintenance costs represents a well-known adaptive strategy displayed by several species of small mammals to cope with adverse conditions and shortage of resources (Bozinovic et al., 2007; Zhu et al., 2013; Yan et al., 2014). Conversely, the influence of social conflict over body size growth is less clear-cut. The reduction of the maximum growth rate in the rats only exposed to social conflict clearly responds to the diminished food consumption. It could be an outcome of the stress response elicited by the social instability and crowding, as demonstrated by the reduction of food intake and the size alteration of the zona glomerulosa of the adrenal cortex. Social instability and crowding are recognized environmental stressors (Blanchard et al., 2001; Chaby et al., 2016), while stress is known to alter feeding responses in a bidirectional pattern, with both increases and decreases in intake (Maniam and Morris, 2012).
The pattern of body size growth is a key life history parameter as it influences age of sexual maturity and henceforth the reproductive potential and success of individuals (Griffiths and Brook, 2005). Indeed, the transition from growth to reproduction produces an observable relationship between age and size at maturity (Berner and Blanckenhorn, 2007). In freeliving Norway rats ( $R$. norvegicus) from temperate and tropical populations, both males and females reach sexual maturity at $\sim 200 \mathrm{~g}$ (Porter et al., 2015), suggesting this as the critical weight threshold which triggers the physiological processes that underlie the reproductive life of the species (Berner and Blanckenhorn, 2007; Porter et al., 2015). Based on this, the rats fed ad libitum (FR-) reached that threshold between the 7th and 8th week of life, while those with limited resources $(F R+)$ matured almost a month later. This would allow the former to initiate breeding earlier, which should enhance its reproductive fitness over food restricted rats.

Despite the remarkable contrast in maximum growth rate, no differences were detected among the maximum growth (represented by the upper asymptote $A$ ) of animals exposed to environmental challenges. The latter might suggest that, if conditions prevailed, the FR- individuals would continue growing until reaching a standard adult size. However, this seems unlikely, since mammals typically present a determinate growth, whereby growth slows considerably after sexual maturity (Mumby et al., 2015). Additionally, when considering the maximum growth rate, the maximum growth might be reached after two years, which greatly surpass the life span of the species.

Body mass is an important consideration in intraspecific competition, thus the larger size of the rats fed ad libitum over those food restricted entails a competitive advantage in encounters. Food restricted individuals would be in a greater disadvantage during the late breeding season, when competition for resources become even more important. This, added to a delayed onset of the breeding season, suggests that the reproductive success of the individuals of smaller size might be jeopardized. Summarizing, the clear divergence on growth patterns among rats exposed to different long-term environmental challenges may represent significant consequences on the individual's life trajectory.

\section{Acknowledgements}

We thank Carolina Panzani, Leandro Neme and Enrique Rebelindo for assistance with experimental procedures. We acknowledge the contributions from two anonymous reviewers, whose comments helped to improve the quality of the manuscript. 
This work was funded by Agencia Nacional de Promoción Científica y Tecnológica [PICT 2012-1552]; and Universidad Nacional del Litoral [CAI+D 2011]. The funders had no role in study design, data collection and analysis, decision to publish, or preparation of the manuscript.

\section{References}

Antinuchi CD, Luna F. 2002. Assessing the effect of litter size on growth pattern and homeothermy acquisition in the Pampas mice Akodon azarae (Rodentia, Muridae). Growth, Dev. Aging 66: 63-69.

Arnold TW. 2010. Uninformative parameters and model selection using Akaike's information criterion. J. Wildl. Manage. 74: 1175-1178.

Beldomenico PM, Begon M. 2010. Disease spread, susceptibility and infection intensity: vicious circles? Trends Ecol. Evol. 25: 21-27.

Berner D, Blanckenhorn WU. 2007. An ontogenetic perspective on the relationship between age and size at maturity. Funct. Ecol. 21: 505-512.

Blanchard R, McKittrick C, Blanchard D. 2001. Animal models of social stress: effects on behavior and brain neurochemical systems. Physiol. Behav. 73: 261-271.

Blanckenhorn WU. 2000. The evolution of body size: what keeps organisms small? Q. Rev. Biol. 75: 385-407.

Bolnick DI, Amarasekare P, Araújo MS, Bürger R, Levine JM, Novak M, Rudolf VHW, Schreiber SJ, Urban MC, Vasseur DA. 2011. Why intraspecific trait variation matters in community ecology. Trends Ecol. Evol. 26: 183-192.

Bozinovic F, Muñoz JLP, Naya DE, Cruz-Neto AP. 2007. Adjusting energy expenditures to energy supply: food availability regulates torpor use and organ size in the Chilean mouse-opossum Thylamys elegans. J. Comp. Physiol. B. 177: 393-400.

Burnham KP, Anderson DR, Huyvaert KP. 2011. AIC model selection and multimodel inference in behavioral ecology: some background, observations, and comparisons. Behav. Ecol. Sociobiol. 65: 23-35.

Burthe SJ, Lambin X, Telfer S, Douglas A, Beldomenico PM, Smith A, Begon M. 2010. Individual growth rates in natural field vole, Microtus agrestis, populations exhibiting cyclic population dynamics. Oecologia 162: 653-661.

Chaby LE, Sheriff MJ, Cavigelli SA, Hirrlinger AM, Lim J, Braithwaite VA. 2016. Stress during adolescence shapes performance in adulthood: context-dependent effects on foraging and vigilance. Ethology 122: 1-14.

Creel S, Dantzer B, Goymann W, Rubenstein DR. 2013. The ecology of stress: effects of the social environment. Funct. Ecol. 27: 66-80

Dantzer B, Newman AEM, Boonstra R, Palme R, Boutin S, Humphries MM, Mcadam AG. 2013. Density triggers maternal hormones that increase adaptive offspring growth in a wild mammal. Science 340: 1215-1218.
De Conto V, Cerqueira R. 2007. Reproduction, development and growth of Akodon lindberghi (Hershkovitz, 1990) (Rodentia, Muridae, Sigmodontinae) raised in captivity. Brazilian J. Biol. 67: 707-713.

Downs CJ, Brown JL, Wone BWM, Donovan ER, Hayes JP. 2016. Speeding up growth: selection for mass-independent maximal metabolic rate alters growth rates. Am. Nat. 187: 295-307.

Eberhardt AT, Costa SA, Marini MR, Racca A, Baldi C, Robles MR, Moreno PG, Beldomenico PM. 2013. Parasitism and physiological trade-offs in stressed capybaras. PLoS One 8: e70382.

English S, Bateman AW, Clutton-Brock TH. 2012. Lifetime growth in wild meerkats: incorporating life history and environmental factors into a standard growth model. Oecologia 169: 143-153.

Griffiths AD, Brook BW. 2005. Body size and growth in tropical small mammals: examining variation using non-linear mixed effects models. J. Zool. 267: 211-220.

Gursoy E, Cardounel A, Hu Y, Kalimi M. 2001. Biological effects of long-term caloric restriction: adaptation with simultaneous administration of caloric stress plus repeated immobilization stress in rats. Exp. Biol. Med. 226: 97-102.

ILAR, 2010. Guide for the Care and Use of Laboratory Animals, 7th edn. Washington, D.C., National Academy Press.

Jackson TP, Van Aarde RJ. 2003. Sex- and species-specific growth patterns in cryptic African rodents, Mastomys natalensis and M. coucha. J. Mammal. 84: 851-860.

Jahn GA, Moya G, Jammes H, Rosato RR. 1995. Effect of chronic thyroid hormone treatment on cycling, ovulation, serum reproductive hormones and ovarian $\mathrm{LH}$ and prolactin receptors in rats. Endocrine 3: 121-127.

Johnson JB, Omland KS. 2004. Model selection in ecology and evolution. Trends Ecol. Evol. 19: 101-108.

Kahm M, Hasenbrink G, Lichtenberg-Fraté H, Ludwig J, Kschischo M. 2010. grofit: fitting biological growth curves with R. J. Stat. Softw. 33: 1-21.

Kriengwatana B, Wada $\mathrm{H}$, Macmillan A, MacDougallShackleton SA. 2013. Juvenile nutritional stress affects growth rate, adult organ mass, and innate immune function in Zebra finches (Taeniopygia guttata). Physiol. Biochem. Zool. 86: 769-781.

Kristan DM. 2007. Chronic calorie restriction increases susceptibility of laboratory mice (Mus musculus) to a primary intestinal parasite infection. Aging Cell 6: 817825.

Labocha MK, Schutz H, Hayes JP. 2014. Which body condition index is best? Oikos 123: 111-119.

Lee DE, Bettaso JB, Bond ML, Bradley RW, Tietz JR, Warzybok PM. 2012. Growth, age at maturity, and age-specific survival of the arboreal salamander (Aneides lugubris) on Southeast Farallon Island, California. J. Herpetol. 46: 64-71.

Maniam J, Morris MJ. 2012. The link between stress and feeding behaviour. Neuropharmacology 63: 97-110.

Merkling T, Leclaire S, Danchin E, Lhuillier E, Wagner RH, White J, Hatch SA, Blanchard P. 2012. Food availability and 
offspring sex in a monogamous seabird: insights from an experimental approach. Behav. Ecol. 23: 751-758.

Mumby HS, Chapman SN, Crawley JAH, Mar KU, Htut W, Thura Soe A, Aung $H H$, Lummaa V, 2015. Distinguishing between determinate and indeterminate growth in a long-lived mammal. BMC Evol. Biol. 15: 214.

Muñoz A, Bonal R. 2008. Are you strong enough to carry that seed? Seed size/body size ratios influence seed choices by rodents. Anim. Behav. 76: 709-715.

Nicolaides NC, Kyratzi E, Lamprokostopoulou A, Chrousos GP, Charmandari E. 2015. Stress, the stress system and the role of glucocorticoids. Neuroimmunomodulation 22: 6-19.

Okie JG, Boyer AG, Brown JH, Costa DP, Ernest SKM, Evans AR, Fortelius M, Gittleman JL, Hamilton MJ, Harding LE, Lintulaakso K, Lyons SK, Saarinen JJ, Smith FA, Stephens PR, Theodor J, Uhen MD, Sibly RM, 2013. Effects of allometry, productivity and lifestyle on rates and limits of body size evolution. Proc. R. Soc. B Biol. Sci. 280: 20131007.

Porter FH, Costa F, Rodrigues G, Farias H, Cunha M, Glass GE, Reis MG, Ko Al, Childs JE, 2015. Morphometric and demographic differences between tropical and temperate Norway rats (Rattus norvegicus). J. Mammal. 96: 317-323.

Preisser EL, Orrock JL. 2012. The allometry of fear: interspecific relationships between body size and response to predation risk. Ecosphere 3: 1-27.

Schmidt KL, Macdougall-Shackleton EA, MacdougallShackleton SA. 2012. Developmental stress has sexspecific effects on nestling growth and adult metabolic rates but no effect on adult body size or body composition in song sparrows. J. Exp. Biol. 215: 32073217.

Ulrich-Lai YM, Figueiredo HF, Ostrander MM, Choi DC, Engeland WC, Herman JP. 2006. Chronic stress induces adrenal hyperplasia and hypertrophy in a subregionspecific manner. Am. J. Physiol. - Endocrinol. Metab. 291: 965-973.

Yan C, Xu T, Cao X, Wang F, Wang S, Hao S, Yang H, Li H, Zhang Z. 2014. Temporal change in body mass of two sympatric hamster species and implications for population dynamics. Can. J. Zool. 92: 389-395.

Zhu W-L, Mu Y, Zhang H, Zhang L, Wang Z-K. 2013. Effects of food restriction on body mass, thermogenesis and serum leptin level in Apodemus chevrieri (Mammalia: Rodentia: Muridae). Ital. J. Zool. 80: 337-344.

Zullinger EM, Ricklefs RE, Redford KH, Mace GM. 1984. Fitting sigmoidal equations to mammalian growth curves. J. Mammal. 65: 607-636. 